\title{
¿Screening o tamizaje?
}

\author{
Alfredo Pinzón • Bogotá, D.C. (Colombia)
}

\section{¿Screening o Tamizaje?}

Aunque es frecuente, el uso de las expresiones "screening" o "tamizaje" en la jerga médica es incorrecto e inaceptable. La primera por tratarse de un anglicismo, y la segunda por ser la inadecuada utilización del sufijo - aje en el verbo "tamizar", que resulta en un vocablo inexistente en nuestro idioma.

En medicina, la acción de examinar un grupo de personas para separar aquellos sanos de los que tienen una condición patológica oculta o alto riesgo de padecerla, generalmente mediante el uso de pruebas diagnósticas o criterios clínicos, puede ser nombrada por medio de dos verbos transitivos que describen esa actividad:

- Tamizar: (tr.): depurar, elegir con cuidado y minuciosidad.

- Cribar: (del latín cribrãre): seleccionar rigurosamente.

De estos verbos se derivan las únicas voces correctas en lengua española para describir esta acción, la primera como nombre sustantivo y la segunda como forma no personal (participio) del verbo:

\section{Tamización o Cribado}

\section{Fuentes:}

- Real Academia Española de la Lengua, consultado en: www.rae.es

- Medical Dictionary, consultado en: www.thefreedictionary.com

- Ruiz A, Morillo LE. Epidemiología Clínica: investigación clínica aplicada.Editorial Médica Panamericana.Bogotá D.C.2004

* Envíe sus inquietudes, sugerencias o comentarios a: actmedco@etb.net.co - alfredo.pinzon@hus.org.co Dr. Alfredo Pinzón Junca: Especialista en Medicina Interna y Psicoanálisis. Hospital Universitario de La Samaritana y Hospital Simón Bolívar. Comité de Educación y Comunicaciones de la ACMI®. Bogotá, D.C. (Colombia).

E-mail: alfredo.pinzon@hus.org.co - alfpin@hotmail.com

Recibido: 24/II/2012 - Aceptado:24/II/2012 